\title{
THE IMPACT OF ORTHOGRAPHIC KNOWLEDGE ON SPEECH PROCESSING
}

\author{
Régine Kolinsky ${ }^{1}$ \\ Fonds de la Recherche Scientifique-Belgium
} Unité de Recherche en Neurosciences Cognitives, Centre de Recherche Neurosciences \& Cognition, Université Libre de Bruxelles

Chotiga Pattamadilok Laboratoire Parole et Langage, Centre de Recherche Neurosciences \& Cognition, Aix-en-Provence

José Morais

Unité de Recherche en Neurosciences Cognitives, Centre de Recherche Neurosciences \& Cognition, Université Libre de Bruxelles

\begin{abstract}
The levels-of-processing approach to speech processing (cf. Kolinsky, 1998) distinguishes three levels, from bottom to top: perception, recognition (which involves activation of stored knowledge) and formal explicit analysis or comparison (which belongs to metalinguistic ability), and assumes that only the former is immune to literacy-dependent knowledge. In this contribution, we first briefly review the main ideas and evidence supporting the role of learning to read in the alphabetic system
\end{abstract}

\begin{tabular}{|l|l|l|l|l|}
\hline Ilha do Desterro & Florianópolis & $n^{\circ} 63$ & p. 161-186 & jul/dez 2012 \\
\hline
\end{tabular}


in the development of conscious representations of phonemes, and we contrast conscious and unconscious representations of phonemes. Then, we examine in detail recent compelling behavioral and neuroscientific evidence for the involvement of orthographic representation in the recognition of spoken words. We conclude by arguing that there is a strong need of theoretical re-elaboration of the models of speech recognition, which typically have ignored the influence of reading acquisition.

(...) if you are abcedminded, to this claybook, what curios of signs (please stoop), in this allaphbed!

Finnegans' Wake James Joyce

Although most current models of speech recognition typically assume that speech is processed without reference to its written code, the influence of orthographic knowledge on lexical and postlexical speech processing has been consistently observed these last twenty years. In the present paper, we will review the behavioral and neuroscientific evidence for such a role, analyzing it by reference to the levels-of-processing approach proposed by Kolinsky (1998). In this approach, three levels, from bottom to top, are distinguished in speech processing: perception, recognition (which involves activation of stored knowledge) and formal explicit analysis (which belongs to metalinguistic ability). Only the first level is supposed to be immune to literacy-dependent knowledge and attentional influences. Here, we will follow the historical (rather than processing) order, starting from metaphonological processing.

Two methods can be used to show that literacy affects speech processing: on the one hand, the comparison between literate and illiterate populations, preferentially adults, which allows to control for possible maturation effects; on the other hand, the study, in 
literate people, of the impact of spelling knowledge on speech processing. Although we will focus on the latter method, reference to data issued from the first one will also be included when relevant for the discussion.

\section{The impact of orthographic knowledge on metaphonological processing}

It is now widely accepted that the ability to read and write strongly impacts on the development of metalinguistic abilities. The role of alphabetic literacy is critical as regards phoneme awareness, and its impact has been untangled from the influence of cognitive maturation by comparing illiterate to ex-illiterate Portuguese adults, the latter having learned to read and write at adult age, in special alphabetization classes. Using tasks that require either to delete the initial consonant of a short verbal expression or to add one at the onset, Morais, Cary, Alegria and Bertelson (1979) showed that illiterates were unable to do either of these tasks (nearly half of them did not make a single correct response), whereas ex-illiterates obtained on the average a reasonably high performance level (nearly half of them succeeded on every trial). These results show that the awareness of phonemes does not develop spontaneously, but is elicited by learning to read and write, at least in an alphabetic system (Read, Zhang, Nie, \& Ding, 1986; Prakash, Rekha, Nigam, \& Karanth, 1993; Nakamura, Kolinsky, Spagnoletti, \& Morais, 1998; Spagnoletti, Morais, Alegria, \& Dominicy, 1989). Although conscious access to syllables or rhyme does not depend so critically on literacy, ex-illiterates also score higher than illiterates in tasks involving such abilities (e.g., Bertelson, De Gelder, Tfouni, \& Morais, 1989; Morais, Bertelson, Cary, \& Alegria, 1986). 
Régine Kolinsky, Chotiga Pattamadilok, and José Morais, The impact...

Not surprisingly, in literates, the tasks that require explicit analysis of sub-lexical units are affected by orthographic knowledge. In 1979, Seidenberg and Tanenhaus reported a congruency effect of word spelling knowledge and phonology in a purely auditory phonological judgment task: the time taken to decide that two spoken words rhyme is shorter when their spellings are similar ("toast-roast") than when they are not ("toast-ghost"), and the opposite effect holds for negative decisions (faster for "leaf-ref" than for "leaf-deaf"). The same year, Ehri and Wilce found that, in phoneme counting, the number of letters influences performance, with beginning readers counting five phonemes in a word like "pitch" (/pit $\left.\int /\right)$, but only four in "rich" (/rit $\left.\int /\right)$. Later on, Castles, Holmes, Neath and Kinoshita (2003) showed that both adults and fifth-grade children are better at deleting or reversing orthographically transparent phonemes, i.e., for which there is a direct correspondence with letters (like deleting /d/ in "dentist"), than more orthographically opaque items in which there is no simple correspondence (like deleting /k/ in "queen").

We ourselves provided a converging demonstration of the influence of word spelling knowledge on adult listeners' metaphonological performance by investigating the explicit and intentional operations called forth when blending two consonant-vowel-consonant (CVC) monosyllabic words (cf. Treiman, 1983, 1986) into a new CVC word (Ventura, Kolinsky, Brito-Mendes \& Morais, 2001). As a matter of fact, Portuguese listeners preferred the C/VC blend (onset vs. rhyme) for words that are spelled with a final consonant (e.g., answering "bel" rather than "bal" for the orthographic monosyllables "bar-mel"), but the $\mathrm{CV} / \mathrm{C}$ blend (onset plus peak vs. coda) for words that are spelled with a final mute "e" (e.g., answering "cul" rather than "kel" for the orthographic disyllables "cure-pele"). This response pattern was observed even when instructions emphasized the importance of 
the "sounds" and even when the words were homophones (e.g., "par" vs. "pare") presented in different contexts including either mute-ewords or final C-words. In addition, we showed that the effect was not due to acoustic-phonetic differences, since it was observed even with a material in which the acoustic portion of the rhyme had been crossed between the stimuli (e.g., the rhymes in "rale" and "sal" were interchanged). Thus, phonological judgments about the structure of the syllable are shaped by the links between phonology and orthography.

We also showed that the influence of orthographic representations extends beyond the domain of sub-lexical elements such as phonemes, rhymes or syllables. Indeed, studying Thai, a language in which tones (i.e., suprasegmental elements) are lexically distinctive and marked orthographically, but not always consistent, we observed an orthographic congruency effect in tasks that require an explicit analysis of tone information, like tone monitoring and same-different tone judgment: better performance was found when both the tone and the tone marker led to the same response than when they led to opposite, competing responses (Pattamadilok, Kolinsky, Luksaneeyanawin, \& Morais, 2008).

On the basis of this bulk of data, some authors argued that metalinguistictasks, in particular those requiring phonemeawareness, are performed by relying only on orthographic representations (Castles \& Colthaert, 2004; Castles et al., 2003). However, although there is a strong association between letter knowledge and performance on phoneme awareness tasks (e.g., Lukatela, Carello, Shankweiler \& Liberman, 1995), the ability to manipulate specific phonemes does not require knowledge of the specific letter-sound correspondence. Indeed, Hulme, Caravolas, Malkova and Brigstocke (2005) showed that both Czech and English children reliably isolated phonemes for which they did not know the corresponding letter. This refutes the idea 
Régine Kolinsky, Chotiga Pattamadilok, and José Morais, The impact...

that phoneme manipulation ability can only develop as a consequence of orthographic (letter-sound correspondence) knowledge.

Nevertheless, one ought to admit that the orthographic effects observed in metaphonological situations probably reflect strategic resorting to word spelling knowledge. Evidence for a strategicbased influence of orthography on speech processing has been provided by Cutler, Treiman and van Ooijen (2010) in a phoneme detection situation. Using this task, Frauenfelder, Seguí and Dijkstra (1990) (see also Dijkstra, Roelofs, \& Fieuws, 1995) had previously shown that adults detect more rapidly orthographically consistent phonemes, for which the phonographemic correspondence is bi-univocal since there exists only one spelling in the language (e.g., in French - the language of the referred study-, /p/), than orthographically inconsistent phonemes like $/ \mathrm{k} /$, which can be spelled in many different ways: "c", "cc", "ch", "cch", "k", "ck", "cu”, "q", "qu", "cqu" . However, using a task in which English listeners had to detect the initial target sounds of isolated English words, Cutler et al. (2010) showed that this holds true only when spelling was rendered salient by the presence in the experiment of many irregularly spelled filler words (e.g., "kneel”, "cough", "pyjamas"). Although Cutler et al. interpret their data as reflecting prelexical processing of speech, we believe that phoneme detection is a metalinguistic task. As a matter of fact, illiterate adults present serious difficulties to detect target phonemes (e.g., Morais et al., 1986). Thus, what Cutler et al.s data show is that the involvement of word spelling is not mandatory in metalinguistic judgments, but strategically motivated, for example, when it might facilitate a decision about phonemes. The impact of orthographic knowledge on spoken word recognition

Much more impressive is the fact that orthographic knowledge impacts not only metaphonological performance, but also the on-line 
processing of spoken words. Ziegler and Ferrand (1998) reported one of the most robust pieces of evidence in favor of this idea, by showing that the French-speaking participants' knowledge of word spelling influences their performance in an auditory lexical decision task. As a matter of fact, French words with rhymes that can be spelled in multiple ways in other words of this language (e.g., the rhyme of the word "nom" can be spelled differently in words like "son", "long", "rond", etc.) produced longer auditory lexical decision latencies and more errors than did words with rhymes that are spelled only one way (e.g., "biche"). Since then, this orthographic consistency effect has been replicated in several languages (e.g., French: Pattamadilok, Morais, Ventura, \& Kolinsky, 2007; Portuguese: Ventura, Morais, Pattamadilok, \& Kolinsky, 2004; English: Ziegler, Petrova, \& Ferrand, 2008) and in other speech on-line tasks like semantic or gender decision (Pattamadilok, Perre, Dufau, \& Ziegler, 2009; Peereman, Dufour, \& Burt, 2009).

Although we identified the event-related brain potentials (ERPs) time-locked correlations of this effect (Pattamadilok et al., 2009; Perre, Pattamadilok, Montant, \& Ziegler, 2009), several questions remain open. In particular, the cognitive mechanisms underlying the orthographic consistency effect, its exact cognitive locus, as well as its precise cerebral basis are still under debate.

\section{How does orthography influence speech recognition? Online vs. offline accounts}

Two hypotheses have been proposed to explain the cognitive mechanisms underlying the orthographic consistency effect. According to the online account (e.g., Ziegler \& Ferrand, 1998), 
Régine Kolinsky, Chotiga Pattamadilok, and José Morais, The impact...

processing speech activates on line the corresponding orthographic code. Supporting this claim, some brain imaging data show that the brain areas involved in written word processing are activated by spoken utterances, at least when listeners process speech actively, as is the case in the auditory lexical decision task. Indeed, in this particular situation, Dehaene, Pegado, Braga, Ventura, Nunes, Jobert, Dehaene-Lambertz, Kolinsky, Morais \& Cohen (2010) found an increase in the activation of the visual word form area (VWFA), an area of the left ventral occipito-temporal cortex (vOTC) involved in written word processing (Cohen, Dehaene, Naccache, Lehéricy, Dehaene-Lambertz, Hénaff, \& Michel,, 2000), in early literate and ex-illiterate adults compared to illiterate adults.

Alternatively, learning to read could also modify the very nature of the lexical representations, leading these to incorporate orthographic information and/or to be more fine-grained (e.g., Muneaux \& Ziegler, 2004; Taft, 2006; Taft \& Hambly, 1985). This developmental or offline account thus assumes that orthographic effects take place within a modified phonological system rather than being due to feedback projections from the orthographic system onto a pure phonological one. The data from both source localization and neurostimulation techniques (transcranial magnetic stimulation, TMS) suggest that this may indeed be the case in tasks requiring lexical processing. The cortical generator of the orthographic consistency effect obtained in auditory lexical decision, and revealed by source localization, has been shown to be within the vicinity of the left auditory cortex (the left supramarginal gyrus, superior temporal gyrus/sulcus, Perre et al., 2009). Coherently, a TMS study (Pattamadilok, Knierim, Duncan, \& Devlin, 2010) reported that disrupting the function of the left supramarginal gyrus, but not of the left vOTC, canceled the orthographic consistency effect obtained in lexical decision. 
Together, theseobservations suggest that orthography contributes to speech recognition both by top-down online mechanisms and by restructuring the very nature of the phonological representations.

We still, however, need to understand what "restructuring" means. Does restructuring occur only in terms of degree of abstraction, or also in terms of grain size, with phonological representations turned more detailed by literacy? Evidence on this point is mitigated. In fact, according to the developmental lexical restructuring hypothesis, which makes no reference to literacy acquisition, children would add phonological detail to lexical representations during development in order to differentiate among increasing numbers of phonologically similar items (Garlock, Walley, \& Metsala, 2001; Metsala \& Walley, 1998; Storkel, 2002; Walley, Metsala, \& Garlock, 2003). Compatible with this idea is the observation of a significant interaction between word frequency and neighborhood density in auditory tasks like word repetition or gating (e.g., Garlock et al., 2001; Metsala, 1997), in which listeners are presented with increasingly longer segments of a spoken word while attempting to identify it (e.g., Grosjean, 1980, 1996). Indeed, this interaction is explained in terms of two functionally distinct and opposing influences of phonological neighbors. The online effect would result from competing similar sound high-frequency words: performance is facilitated for words from sparse as opposed to dense neighborhoods. The off-line effect would reflect pressures for segmental restructuring of words resembling many others: it affects the processing of low-frequency words, for which performance is better for words from dense as opposed to sparse neighborhoods. Using a gating and a word identification-in-noise task, we showed a similar interaction in illiterate adults (Ventura, Kolinsky, Fernandes, Querido, \& Morais, 2007). Thus, lexical restructuring, in that sense, seems to occur in the absence of literacy. 
But these results do not imply that there is no effect at all of literacy acquisition on the representations of speech. More research is needed to answer this question, taking into account the level of abstraction and awareness of representations. In the next section, we address a distinct but related question, namely how precociously may literacy influence the dynamics of speech processing, and in particular whether such an influence may already occur at a prelexical stage.

\section{Does orthographic knowledge and literacy only influence lexical representations or more basic, perceptual, speech processes?}

Given the tight relation between speech and orthography, if one assumes that the phonological representations of literate people have been modified by their acquisition of orthographic knowledge, one might expect the orthographic consistency effect to occur in any speech recognition task. This is indeed the case, but with one important exception, namely, the shadowing task, in which the listener has to repeat as rapidly as possible any spoken sequence, be it a word or a pseudo-word. Contrary to lexical decision or semantic judgment, the shadowing response does not rely on any binary choice decision and requires only a precise analysis of the phonetic properties of the stimulus (word or pseudoword) in order to build an articulatory plan. The few studies that investigated the orthographic consistency effect in this task have almost always reported negative results.

We were the first to explore the influence of orthographic consistency in shadowing (Ventura et al., 2004). The absence of the orthographic consistency effect in the standard version of this task, combined with the fact that the effect was found in lexical decision and in lexically contingent shadowing, in which participants had to repeat the stimulus only when it was a word, but not in phonemically 
contingent shadowing, in which participants had to repeat the stimulus only when it started with a pre-specified phoneme, led us to conclude that only lexical processes are affected by orthographic knowledge. Pattamadilok et al. (2007) confirmed this finding in a language (French) whose written code is orthographically more inconsistent than the one of the language tested in Ventura et al's study (Portuguese). Pattamadilok et al. showed in addition a systematic association between the occurrence (or not) of the orthographic consistency effect and of the word frequency effect. To our knowledge, the study by Ziegler, Ferrand and Montant (2004) was the only one that showed an orthographic consistency effect in shadowing. Yet, their finding could be explained by the fact that only word stimuli were presented, which may have induced the participants to perform the task at the lexical level. Moreover, the effect may have been contaminated by the number of orthographic neighbors that differed between consistent and inconsistent words, which was not the case in our French study (Pattamadilok et al., 2007).

The whole ensemble of data thus suggests that lexical access is critical for the occurrence of the orthographic consistency effect. Both the on-line and the off-line views can accommodate this fact. However, examining why literate people do not show this effect in shadowing may provide some further information on the cognitive mechanisms of the effect.

This is what we did in a recent study (Pattamadilok, Morais, \& Kolinsky, 2011) in which we compared the occurrence of the orthographic consistency effect in two versions of the shadowing task, namely, when the speech signal was clearly presented (the silent condition) and when its quality was degraded by adding noise (the noise condition). The result obtained in the silent situation replicated the findings previously obtained by Ventura et al. (2004) 
172 Régine Kolinsky, Chotiga Pattamadilok, and José Morais, The impact...

and Pattamadilok et al. (2007): there was no hint of an orthographic consistency effect. On the contrary, when background noise was added to the speech signal, the overall performance level decreased and orthographic consistency affected both reaction times (RTs) and accuracy (at least for high-frequency words), with better performance for consistent words. Thus, increasing task difficulty may, under some circumstances, induce changes in the processes involved in performing a task. Here, when the acoustic signal was clear, speech could be accurately perceived and reproduced only on the basis of the acoustic information. But when the acoustic signal was degraded, the speech processing system had to resort to the redundancy that is present at the level of orthographic representations.

This interpretation does not imply that all orthographic effects are dependent on attentional, strategic processes. On the contrary, we recently showed that such effects can even occur with unattended speech, namely using a passive oddball protocol in which participants watched silent movies and were required to ignore the auditory stimulation (Pattamadilok, Morais, Colin, \& Kolinsky, submitted). As a matter of fact, in a situation in which we manipulated the orthographic congruency between frequent (e.g., "tri", /tRi/) and deviant spoken words, we observed a stronger electrophysiological Mismatch Negativity ( $M M N)$ response to the orthographically incongruent (e.g., "prix", /pRi/) than to the orthographically congruent (e.g., "cri", /kRi/) deviant spoken word. Since the MMN is an automatic index of experience-dependent auditory memory traces, this shows a profound, attention-independent, impact of spelling knowledge on the speech processing system.

Nevertheless, not all early perceptual processes are affected by orthographic knowledge or, more generally, by literacy. Studies on illiterate people have shown them to be quite able to make phonetic 
discriminations, presenting almost perfect scores for differentiating for instance "faca" (knife) from "vaca" (cow) while being very poor at manipulating phonemes explicitly (Adrián, Alegria, \& Morais, 1995; Loureiro, Braga, do Nascimento Souza, Nunes Filho, Queiroz, \& Dellatolas, 2004; Scliar-Cabral, Morais, Nepomuceno, \& Kolinsky, 1997). In comparison to literates, illiterates also present the same phenomenon of categorical perception of speech sounds, as estimated through the relation between identification and discrimination performances (Serniclaes, Ventura, Morais, \& Kolinsky, 2005). Still, literacy seems to modulate boundary precision, with literates showing a steeper identification slope than illiterates. Although in our study this effect could be attributed to a lexical bias (one of the end points of the continuum used by Serniclaes et al. was a word in Portuguese: "da", while the other, /ba/, was not), a similar effect was recently reported in a developmental study. Examining 6-8 years-old children and adults with a voicing (/de-te/) continuum, Hoonhorst, Medina, Colin, Markessis, Radeau and Deltenre (2011) reported no effect of age on categorical perception per se, but observed that boundary precision increased with age and was correlated with reading level.

Thus, although the data do not confirm the strong hypothesis according to which perceptual categorization of speech sounds depends on reading acquisition (Burnham, 2003), they suggest notwithstanding that literacy helps in finely tune phonological boundaries and hence in increasing the precision of phoneme identification.

Additional evidence for modification of the auditory system by reading acquisition comes from our functional magnetic resonance imaging (fMRI) study, in which we observed increased activation of the planum temporale $(P T)$ in early literates and ex-illiterates 
compared to illiterates in listening to speech (Dehaene et al., 2010). Direct on-line feedback from orthography to phonology is not a very plausible interpretation of the enhanced PT activation observed in literates, as PT activates only in response to auditory input, not to written words (Dehaene et al., 2010) or isolated letters (Van Atteveldt, Formisano, Goebel, \& Blomert, 2004). Still, PT activation may itself be modulated by on-line feedback from multimodal regions (superior temporal sulcus and superior temporal gyrus) that participate in the audio-visual integration of isolated letters and phonemes, reacting to their congruence (van Atteveldt et al., 2004).

\section{The developmental pace of the influence of orthographic knowledge on speech processing}

The feedback connections and/or restructuring process take place rapidly in the course of learning to read. We demonstrated this in our developmental studies: the orthographic consistency effect emerges after about one and a half year of reading classes in both Portuguese and French (Pattamadilok, Morais, De Vylder, Ventura, \& Kolinsky, 2009; Ventura, Kolinsky, Pattamadilok, \& Morais, 2008; Ventura, Morais, \& Kolinsky, 2007). Interestingly, in both languages this effect is initially a generalized one: contrary to adults, secondgraders present a consistency effect for both words and pseudowords, in both lexical decision and shadowing. We interpreted this as reflecting the intensive use of sublexical units (viz., the graphemephoneme and phoneme-grapheme correspondences) at this stage of literacy acquisition, which contributes to establish a vivid flow of information between sublexical orthographic and phonological representations in the processing system. 
However, the pace at which the orthographic consistency effect reaches the adult pattern (characterized by a limitation of the effect to lexical decision and to words) depends on the orthographic transparency of the written code, with an earlier shift from the beginning reader to the adult's pattern in French than in Portuguese. Whereas in French the adult pattern was reached during the third grade (Pattamadilok et al., 2009), in Portuguese it was reached only two or even three years later (Ventura et al., 2008). This suggests that, in the course of literacy acquisition, the overall orthographic inconsistency of the language's orthographic code influences the rate at which orthographic representations impact on spoken word recognition: given that French orthography is much more inconsistent than Portuguese, frequent confrontation with the inefficiency of the sublexical decoding strategy may induce French children to develop lexical orthographic representations of words earlier than their Portuguese peers.

\section{Are there other effects of literacy on speech processing?}

As for literate adults (e.g., Baddeley, 1966; Conrad \& Hull, 1964), illiterate's immediate ordered recall performance is worse when items sound similar, for example, when they rime, than when they do not, thus showing that they spontaneously use phonological codes in short-term memory (Morais et al., 1986). However, they reach far lower performance compared to literates in verbal memory tasks (Morais et al., 1986; see also discussions in Morais \& Kolinsky, $2001,2002,2005)$. Since ex-illiterates also obtain far poorer scores than early literates, part of this effect may be linked to experience and organizational processes obtained through schooling. However, it is 
also possible that in literates spelling knowledge helps maintaining the representation of spoken strings in memory. Under this view, the ex-illiterates' low reading ability does not allow the automatic activation of orthographic representations in verbal memory tasks.

The notion that spelling knowledge helps maintaining the representation of spoken strings in memory was supported recently (Pattamadilok, Lafontaine, Morais, \& Kolinsky, 2010). Using serial recall of auditory seven-word lists, we observed that, compared to the situation where words shared neither the phonological nor the orthographic rime (as in the list "fric, grade, loge, taule, coupe, blanche, moche"), inter-item orthographic dissimilarity, viz. when words ended with the same inconsistent rime, e.g., /or/, but did not always share their spelling (as in the list "sport, nord, chlore, bord, flore, corps, tort") assists verbal working memory by reducing or even avoiding the detrimental effect of phonological similarity, viz. when words ended with the same inconsistent rime, e.g. /as/ and shared the same spelling (as in the list "classe, brasse, chasse, passe, masse, basse, casse"). This orthographic modulation of the phonological similarity effect only occurred at positions four to six of the word list. Recall performance at position seven benefited from a recency effect that may be assumed to result from a more surfacelevel (acoustic-phonetic) representation, while better performance at positions one to three is attributable to primacy effects, and can be accounted for in terms of consolidation through recapitulation. The beneficial influence of orthographic knowledge may, therefore, be only apparent when the item stored in short-term memory takes the form of an abstract but unconsolidated phonological representation, which in fact corresponds to the harder to remember serial positions. 


\section{Conclusion}

All the most influential current models of spoken word recognition lack an account of the orthographic effects that we reviewed in the present paper.

For instance, the Cohort model (Marslen-Wilson \& Tyler, 1980; Marslen-Wilson \& Welsh, 1978) claims that the word-initial cohort is constructed from the phonological information contained in a spoken word. Thereby, the cohort consists of all spoken words that share the same initial segment(s) of the input word. Although high-level information such as semantic, syntactic or contextual information also plays a role by eliminating competitors from the cohort, the contribution of word spelling, which is a form of lexical knowledge, is totally ignored.

The absence of interaction between the phonological information and the corresponding orthographic information is inherent to autonomous models such as RACE or MERGE (Cutler \& Norris, 1979; Norris, McQueen, \& Cutler, 2000). But, strangely, the role of orthography is not mentioned either in a highly interactive model such as TRACE (McClelland \& Elman, 1986), although this could easily accommodate the impact of orthography on spoken word recognition by means of interactions between the representations activated at different levels (i.e., features, phonemes, and words).

Full interactivity between phonology and orthography, as proposed for example in the bimodal interactive activation model (Grainger \& Ferrand, 1994, 1996), which assumes systematic interaction by means of a single mechanism, does not seem to reflect all the data, either. As we discussed here, behavioral orthographic effects are not general, since they do not occur when the task can be made without reference to the lexicon. However, as indicated above, 
physiological measurements show an influence of orthography on speech processing even when words are not attended to.

There is thus a strong need of theoretical re-elaboration of the models of speech recognition, to make them able to integrate the influence of orthographic knowledge on spoken word processing.

On the one hand, if literacy acquisition is a "virus", as proposed by Frith (1998, p. 1051), it does not seem to "infect all speech processing", as illustrated by the lack of influence of spelling knowledge in most shadowing situations, and the absence of literacy effect on speech discrimination (Adrián et al., 1995; Loureiro et al. 2004; ScliarCabral et al., 1997), on the classic estimation of categorical perception (Serniclaes et al., 2005) and on other perceptual phenomena such as phonetic feature blendings and migration of speech properties (Morais, Castro, Scliar-Cabral, Kolinsky, \& Content, 1987; Morais \& Kolinsky, 1994; see also other data in Cutler \& Davis, 2012, and discussions in Morais \& Kolinsky, 2001, 2002, 2005).

On the other hand, the available evidence is also only partly compatible with Kolinsky's (1998) levels-of-processing approach to speech processing. This assumed the perceptual level to be immune to literacy-dependent knowledge and attentional influences. However, modulation (perhaps indirect) of speech perception regions (like the PT) by visual information (Van Atteveldt et al., 2004) and literacy (Dehaene et al., 2010) as well as literacy effects on some perceptual processes like phonemic boundary precision (Hoonhorst et al., 2011; Serniclaes et al., 2005) suggest that some, though not all, perceptual processes might be affected by literacy-dependent knowledge. At the other extreme of the processing path, it is worth noting that metalinguistic performance is not always "infected" by letter (Hulme et al., 2005) and spelling (Cutler et al., 2010) knowledge either. Future studies are thus needed to better identify the conditions and extent of 
the influence of literacy-related knowledge on both perceptual and metalinguistic processes and representations.

\section{Note}

1. Corresponding author:

Régine Kolinsky

UNESCOG

Université Libre de Bruxelles, CP 191

50 Av. F. Roosevelt

B-1050 Brussels, Belgium

e-mail: rkolins@ulb.ac.be

\section{References}

Adrián, J. A., Alegria, J. \& Morais, J. (1995). Metaphonological abilities of Spanish illiterate adults. International Journal of Psychology, 30, 329-353.

Baddeley, A. D. (1966). Short-term memory for sequences as a function of acoustic, semantic and formal similarity. Quarterly Journal of Experimental Psychology, 18, 362-365.

Bertelson, P., de Gelder, B., Tfouni,L. V. \& Morais, J. (1989). Metaphonological abilities of adult illiterates : New evidence on heterogeneity. European Journal of Cognitive Psychology, 1, 239-250.

Burnham, D. K. (2003). Language specific speech perception and the onset of reading. Reading and Writing, 16, 573-609.

Castles, A. \& Coltheart, M. (2004). Is there a causal link from phonological awareness to success in learning to read? Cognition, 91, 77-111.

Castles, A., Holmes, V. M., Neath, J. \& Kinoshita, S. (2003). How does orthographic knowledge influence performance on phonological awareness tasks? Quarterly Journal of Experimental Psychology, 56A, 445-467.

Cohen, L., Dehaene, S., Naccache, L., Lehéricy, S. Dehaene-Lambertz, G., Hénaff, M. A. \& Michel, F. (2000). The visual word form area: spatial and temporal characterization of an initial stage of reading in normal subjects and posterior split-brain patients. Brain, 123, 291-307. 
Conrad, R., \& Hull, A. J. (1964). Information, acoustic confusion and memory span. British Journal of Psychology, 55, 429-432.

Cutler, A., \& Norris, D. (1979). Monitoring sentence comprehension, in W.E. Cooper \& E.C.T. Walker (Eds.) Sentence processing: psycholinguistic studies presented to Merrill Garrett. Hillsdale, NJ: Lawrence Erlbaum.

Cutler, A., \& Davis, C. (2012). An orthographic effect in phoneme processing, and its limitations. An orthographic effect in phoneme processing, and its limitations. Frontiers in Psychology, 3,18.

Cutler, A., Treiman, R., \& Van Ooijen, B. (2010). Strategic deployment of orthographic knowledge in phoneme detection. Language and Speech, 53, 307-320.

Dehaene, S., Pegado, F., Braga, L. W., Ventura, P., Nunes, G. Jobert, A., Dehaene-Lambertz, G., Kolinsky, R., Morais, J., \& Cohen, L. (2010). How learning to read changes the cortical networks for vision and language. Science, 330, 1359-1364.

Dijkstra, T., Roelofs, A. \& Fieuws, S. (1995). Orthographic effects on phoneme monitoring. Canadian Journal of Experimental Psychology, 49, 264-271.

Ehri, L. C. \& Wilce, L. S. (1979). The mnemonic value of orthography among beginning readers. Journal of Educational Psychology, 71, 26-40.

Frauenfelder, U. H., Seguí, J. \& Dijkstra, T. (1990). Lexical effects in phonemic processing: Facilitatory or inhibitory? Journal of Experimental Psychology: Human Perception and Performance, 16, 77-91.

Frith, U. (1998). Editorial: Literally changing the brain. Brain, 121, 10511052

Garlock, V. M., Walley, A. C. \& Metsala, J. L. (2001). Age-of-acquisition, word frequency, neighborhood density effects on spoken word recognition by children and adults. Journal of Memory and Language, $45,468-492$.

Grainger, J., \& Ferrand, L. (1994). Phonology and orthography in visual word recognition: Effects of masked homophone primes. Journal of Memory and Language, 33, 218-218. 
Grainger, J., \& Ferrand, L. (1996). Masked orthographic and phonological priming in visual word recognition and naming: Cross-task comparisons. Journal of Memory and Language, 35, 623-647.

Grosjean, F. (1980). Spoken word recognition processes and the gating paradigm. Perception \& Psychophysics, 28, 267-283.

Grosjean, F. (1996). Gating. Language and Cognitive Processes, 11, 597-604.

Hoonhorst, I., Medina, V., Colin, C., Markessis, E., Radeau, M., Deltenre, P., \& Serniclaes, W. (2011). Categorical perception of voicing, colors and facial expressions: A developmental study. Speech Communication, 53, 417-430.

Hulme, Ch., Caravolas, M., Malkova, G. \& Brigstocke, S. (2005). Phoneme isolation ability is not simply a consequence of letter-sound knowledge. Cognition, 97, B1-B11.

Kolinsky, R. (1998). Spoken word recognition: A stage-processing approach of language differences. European Journal of Cognitive Psychology, 10, $1-40$.

Loureiro, C. D, Braga, L. W., do Nascimento Souza, L. D., Nunes Filho, G., Queiroz, E. \& Dellatolas, G. (2004). Degree of illiteracy and phonological and metaphonological skills in unschooled adults. Brain and Language, 89, 499- 502.

Lukatela, K., Carello, C., Shankweiler, D., \& Liberman, I. Y. (1995). Phonological awareness in illiterates: Observations from SerboCroatian. Applied Psycholinguistics, 16, 463-487.

Marslen-Wilson, W., \& Tyler, L. K. (1980). The temporal structure of spoken language understanding. Cognition, 8, 1-71.

Marslen-Wilson, W., \& Welsh, A. (1978). Processing interactions and lexical access during word recognition in continuous speech. Cognitive Psychology, 10, 29-63.

McClelland, J. L., \& Elman, J. L. (1986). The TRACE model of speech perception. Cognitive Psychology, 18, 1-86.

Metsala, J. L. (1997). An examination of word frequency and neighborhood density in the development of spoken-word recognition. Memory \& Cognition, 25, 47-56. 
Metsala, J. L. \& Walley, A. C. (1998). Spoken vocabulary growth and the segmental restructuring of lexical representations: Precursors to phonemic awareness and early reading ability. In J. L. Metsala \& L. C. Ehri (Eds.), Word Recognition in Beginning Literacy (pp. 89-120). Hillsdale: Erlbaum.

Morais, J., Bertelson, P., Cary, L. \& Alegria, J. (1986). Literacy training and speech segmentation. Cognition, 24, 45-64.

Morais, J., Cary, L., Alegria, J. \& Bertelson, P. (1979). Does awareness of speech as a sequence of phones arise spontaneously? Cognition, 7, 323-331.

Morais, J., Castro, S.-L., Scliar-Cabral, L., Kolinsky, R., \& Content, A. (1987). The effects of literacy on the recognition of dichotic words. Quarterly Journal of Experimental Psychology, 39 A, 451-465.

Morais, J., \& Kolinsky, R. (1994). Perception and awareness in phonological processing the case of the phoneme. Cognition, 50, 287-297.

Morais, J. \& Kolinsky, R. (2001). The literate mind and the universal human mind. In E. Dupoux (Ed.), Language, Brain and Cognitive Development: Essays in honor of Jacques Mehler (pp. 463-480). Cambridge, Mass: M.I.T. Press.

Morais, J. \& Kolinsky, R. (2002). Literacy effects on language and cognition. In L. Bäckman \& C. von Hofsten (Eds.) Psychology at the turn of the millenium, Vol. 1: Cognitive, biological, and health perspectives (pp. 507530). Hove, UK: Psychology Press.

Morais, J. \& Kolinsky, R. (2005). Literacy and cognitive change. In M. Snowling \& C. Hulme (Eds). The science of reading, a Handbook (pp. 188-203). Oxford: Blackwell.

Muneaux, M. \& Ziegler, J. C. (2004). Locus of orthographic effects in spoken word recognition: Novel insights from the neighbour generation task. Language and Cognitive Processes, 19, 641-660.

Nakamura, M., Kolinsky, R., Spagnoletti, C. \& Morais, J. (1998). Phonemic awareness in alphabetically literate Japanese adults: the influence of the first acquired writing system. Cahiers de Psychologie Cognitive /Current Psychology of Cognition, 17, 417-450. 
Norris, D., McQueen, J. M., and Cutler, A. (2000). Merging information in speech recognition: Feedback is never necessary. Behavioral and Brain Sciences, 23, 299-325.

Pattamadilok, C., Knierim, I. N., Duncan, K. J. \& Devlin, J. T. (2010). How does learning to read affect speech perception? Journal of Neuroscience, 30, 8435- 8444 .

Pattamadilok, C., Kolinsky, R., Luksaneeyanawin, S., \& Morais, J. (2008). Orthographic congruency effects in the suprasegmental domain: evidence from Thai. Quarterly Journal of Experimental Psychology, 61, 1515-1537.

Pattamadilok, C., Lafontaine, H., Morais, J., \& Kolinsky, R. (2010). Auditory word serial recall benefits from orthographic dissimilarity. Language and Speech, 53, 321-341.

Pattamadilok, C., Morais, J., Colin, C., \& Kolinsky, R. (submitted). Unattentive speech processing is affected by reading acquisition: Evidence from Mismatch Negativity.

Pattamadilok, C., Morais, J., De Vylder, O., Ventura, P., \& Kolinsky, R. (2009). The orthographic consistency effect in the recognition of French spoken words: an early developmental shift from sub-lexical to lexical orthographic activation. Applied Psycholinguistics, 30, 441-462.

Pattamadilok, C., Morais, J., \& Kolinsky, R. (2011). Naming in noise: the contribution of orthographic knowledge to speech repetition. Frontiers in Psychology, 2, 361.

Pattamadilok, C., Morais, J., Ventura, P. \& Kolinsky, R. (2007). The locus of the orthographic consistency effect in auditory word recognition: Further evidence from French. Language and Cognitive Processes, 22, 700-726.

Pattamadilok, C., Perre, L., Dufau, S., \& Ziegler, J. C. (2009). On-line orthographic influences on spoken language in a semantic task. Journal of Cognitive Neuroscience, 21, 169-179.

Peereman, R., Dufour, S., \& Burt, J. S. (2009). Orthographic influences in spoken word recognition: The consistency effect in semantic and gender categorization tasks. Psychonomic Bulletin \& Review, 16(2), 363-368. 
Perre, L., Pattamadilok, C., Montant, M., \& Ziegler, J. C. (2009). Orthographic effects in spoken language: On-line activation or phonological restructuring? Brain Research, 1275, 73-80.

Prakash, P., Rekha, D., Nigam, R. \& Karanth, P. (1993). Phonological awareness, orthography and literacy. In R. Scholes (Ed.), Literacy and Language Awareness. Hillsdale: NJ Erlbaum, 55-70.

Read, C., Zhang, Y., Nie, H. \& Ding, B. (1986). The ability to manipulate speech sounds depends on knowing alphabetic reading. Cognition, 24, 31-44.

Scliar-Cabral, L., Morais, J., Nepomuceno, L. \& Kolinsky, R. 1997. The awareness of phonemes: So close - so far away. International Journal of Psycholinguistics, 13, 211-240.

Seidenberg, M. S. \& Tanenhaus, M. K. (1979). Orthographic effects on rhyme monitoring. Journal of Experimental Psychology: Human Learning and Memory, 5, 546-554.

Serniclaes, W., Ventura, P., Morais, J. \& Kolinsky, R. (2005). Categorical perception of speech sounds in illiterate adults. Cognition, 98, B35-B44.

Spagnoletti, C., Morais, J., Alegria, J. \& Dominicy, M. (1989). Metaphonological abilities of Japanese children. Reading and Writing, 2, 221-244.

Storkel, H. L. (2002). Restructuring of similarity neighborhoods in the developing mental lexicon. Journal of Child Language, 29, 251-274.

Taft, M. (2006). Orthographically influenced abstract phonological representation: Evidence from non-rhotic speakers. Journal of Psycholinguistic Research, 35, 67-78.

Taft, M. \& Hambly, G. (1985). The influence of orthography on phonological representations in the lexicon. Journal of Memory and Language, 24, 320-335.

Treiman, R. (1983). The structure of spoken syllables: Evidence from novel word games. Cognition, 15, 49-74.

Treiman, R. (1986). The division between onsets and rimes in English syllables. Journal of Memory and Language, 25, 476-491. 
Van Atteveldt, N., Formisano, E., Goebel, R., \& Blomert, L. (2004). Integration of letters and speech sounds in the human brain. Neuron, 43, 271-282.

Ventura, P., Kolinsky, R., Brito-Mendes, C. \& Morais, J. (2001). Mental representations of the syllable internal structure are influenced by orthography. Language and Cognitive Processes, 16, 393-418.

Ventura, P., Kolinsky, R., Fernandes, S., Querido, L., \& Morais, J. (2007). Lexical restructuring in the absence of literacy. Cognition, 105, 334-361.

Ventura, P., Kolinsky, R., Pattamadilok, C., \& Morais, J. (2008). The developmental turn-point of orthographic consistency effects in speech recognition. Journal of Experimental Child Psychology, 100, 135-145.

Ventura, P., Morais, J., \& Kolinsky, R. (2007). The development of the orthographic consistency effect in speech recognition: from sublexical to lexical involvement. Cognition, 105, 547-576.

Ventura, P., Morais, J., Pattamadilok, C. \& Kolinsky, R. (2004). The locus of the orthographic consistency effect in auditory word recognition. Language and Cognitive Processes, 19, 57-95.

Walley, A., C., Metsala, J. L. \& Garlock, V. M. (2003). Spoken vocabulary growth: Its role in the development of phoneme awareness and early reading ability. Reading and Writing, 16, 5-20.

Ziegler, J. C. \& Ferrand, L. (1998). Orthography shapes the perception of speech: The consistency effect in auditory recognition. Psychonomic Bulletin \& Review, 5, 683-689.

Ziegler, J. C, Ferrand, L., \& Montant, M. (2004). Visual phonology: The effect of orthographic consistency on different auditory word recognition tasks. Memory \& Cognition, 32, 732-741.

Ziegler, J. C., Petrova, A., \& Ferrand, L. (2008). Feedback Consistency Effects in Visual and Auditory Word Recognition: Where Do We Stand After More Than a Decade? Journal of Experimental Psychology Learning: Memory and Cognition, 34, 643-661. 
186 Régine Kolinsky, Chotiga Pattamadilok, and José Morais, The impact...

\section{Acknowledgements}

Régine Kolinsky is Research Director of the Fonds de la Recherche Scientifique-FNRS, Belgium.

Preparation of this article was supported by a Belgian FRFC grant (2.4515.12) "Cognitive and brain plasticity in learning to read: comparing early, late, missing and failed literacy".

[Received in January 24th, 2012, Accepted in July 2nd, 2012] 